\title{
Shaeer's purse-string closure of inflatable penile implant corporotomies
}

\author{
Original \\ Article \\ "Osama Shaeer, Kamal Shaeer, Islam Fathy Soliman Abdel Rahmann \\ Department of Andrology, Kasr El Aini Faculty of Medicine, Cairo University, Cairo, \\ Egypt
}

\begin{abstract}
Introduction: In order to close the corporotomies over an inflatable penile implant, one of the two approaches are utilized, either oversewing with running sutures or tying the stay sutures on either sides of the corporotomies. The former has the advantage of being watertight thereby avoiding hematoma formation, and the disadvantages are the risk of puncturing the implant cylinders and the process is time consuming.

Aim: The technique herein provides watertight closure of the corporotomies with short operative time as an alternative.

Patients and Methods: Before insertion of the implant cylinders, a continuous suture line is preplaced in the form of an inverted $U$ around the corporotomies on both corpora, using Vicryl 20/ suture material. Following insertion of the implant, the ends of the suture lines are pulled tight and tied as a purse string. The technique was applied in 18 cases of three-piece inflatable implants.

Results:Overall, the purse-string technique closed the corporotomies successfully in $18100 \%$ ) $18 /$ ) cases of the three-piece inflatable penile prostheses. Neither hematomas nor puncturing of the cylinders were encountered.

Conclusion: Shaeer's purse-string closure of penile implant corporotomies provides watertight closure with short operative time as an alternative to oversewing and tying the stay sutures.
\end{abstract}

Key Words: Corporotomy, penile implant, penile prosthesis, sutureless, water-tight purse-string

Received:29 May 2018, Accepted:09 July 2018

Corresponding Author: Osama Shaeer, MD, PhD, 21 Gaber Ibn Hayan Street, Dokki, Egypt, Zip Code: 12311, Tel.: +201006600606, Fax:+20237605181, E-mail: dr.osama@alrijal.com

ISSN: 2090-6048, June 2018, Vol. 8, No. 2

\section{INTRODUCTION}

Management of erectile dysfunction can be done in many different ways either using oral medications like 'phosphodiesterase inhibitors,' intracavernosal injection, vacuum constriction device, or penile prosthesis implantation. However, there are dropout reaches of up to $80 \%$ in the literature in nonsurgical modalities ${ }^{[1,2]}$. Penile prosthesis implantation surgery is a minimally invasive procedure for the restoration of sexual potency in men with erectile dysfunction with a high, long-term satisfaction rate $^{[3-5]}$. Inflatable penile prosthesis (IPP) has the highest rate of both patient and partner satisfaction as it simulates natural erection and gives better cosmetic effect ${ }^{[5-7]}$. However, this type of operation is not without complications. The most common complications associated with IPP implantation are fluid leak from the device, aneurysm, and dilation of the cylinders, and supersonic transport deformity ${ }^{[8]}$. Moreover, with the IPP being the preferred implant types, there is a risk of puncturing the cylinders during oversewing, with subsequent mechanical failure of the implant. Some surgeons prefer to do corporotomy closure while placing a metal or a plastic shield over the device to protect it from the tip of the needle ${ }^{[9]}$. Another method for closure of corporotomies is to tie the stay suture in a horizontal mattress suture using polyglactin $2 / 0^{[10]}$. In addition, meticulous oversewing is time consuming and lengthens the operative time. More implanters are shifting to closing the corporotomies with the technique of converting the stays to a horizontal mattress and tying them (tying the stay sutures) ${ }^{[9]}$.

\section{AIM OF THE WORK}

The present study represents Shaeer's purse-string closure of inflatable penile implant corporotomies as a watertight technique for the closure of corporotomies, with a short operative time, as an alternative to oversewing and tying the stay sutures.

\section{MATERIALS AND METHODS}

Ethical approval of the institutional review board and patient consents have been obtained.

In all, 18 patients were included in the study who underwent IPP as a treatment of erectile dysfunction not responding to oral medications nor intracavernosal injection. The basic principle is preplacement of a running suture line around the corporotomies before insertion of the implant, by which the edges are pulled together as a purse string after insertion of the cylinders, closing the corporotomies. The technique was applied in 18 cases 
with a three-piece IPP manufactured by Coloplast Corp. (Minneapolis, Minnesota, USA). Incision was peno-scrotal in all cases. Tunica albuginea was exposed at the site of the intended corporotomies. Stay sutures were placed on either side of each corporotomy. The purse-string full thickness corporal suture was then placed around the site of the corporotomies, as a continuous running suture line in the form of an inverted $\mathrm{U}$, using Vicryl 2/0 suture material which can hold its tensile strength for $\sim 2-3$ weeks in tissue, and is completely absorbed by hydrolysis ${ }^{[11,12]}$. The corporotomy was incised inside the U-shaped pursestring suture (Fig. 1).

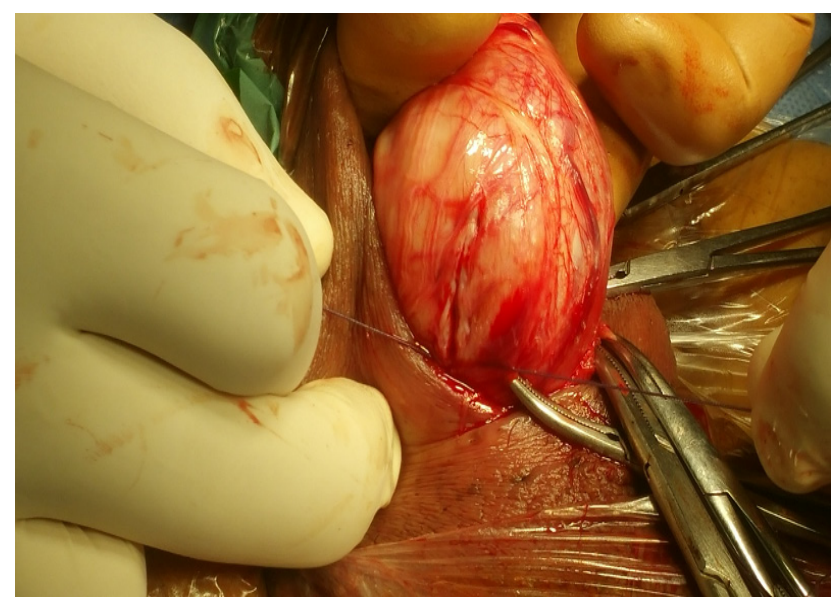

Fig. 1: Pre-placement of the purse-string suture line.

The lower angle of the corporotomy was 1-2 mm cephalad to the caudal ends of the suture line (tips of the inverted $U$ ) so that the exit sites of the tubing (just caudal to the knot) would be properly sealed (Fig. 2). Before insertion of the implant, we avoided pulling on the suture line so as not to narrow the corporotomies down.

Following insertion of the implant, the ends of the suture lines were pulled tight as a purse string and tied (Fig. 2). During pulling on the suture line, the flaccid implant cylinders were dipped-in by the tip of a hemostat, and the tubing (held in a Babcock forceps) was pulled down caudally. The center of the purse string was checked for leakage, in which case, tying the stay sutures over the purse string closed the leaking point can be placed if needed. A drain was not inserted in any of the 18 cases.

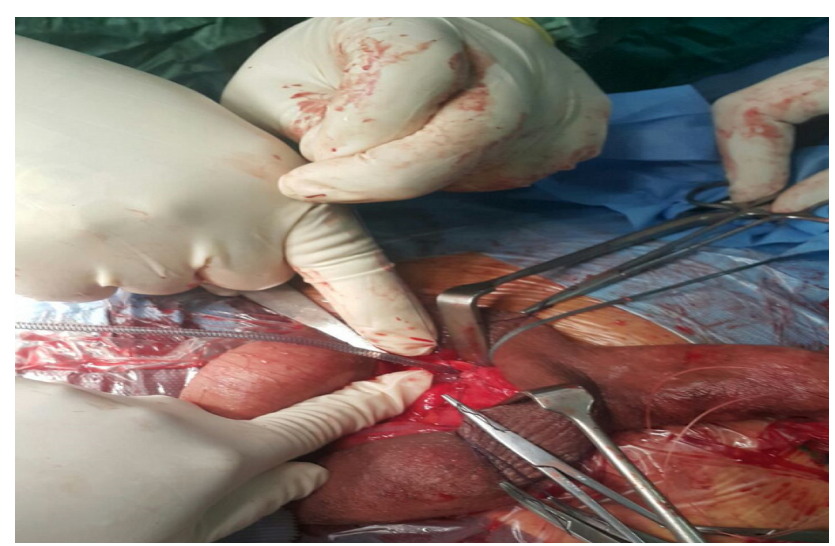

Fig. 2: Tying the purse-string \& Corporotomies closed.

\section{RESULTS}

Implantation was straightforward in all cases. No corporal fibrosis was noticed in all cases. The average operative time was $41 \pm 10.2 \mathrm{~min}$. After tying the purse string, central point leakage was not noted in all cases $(n=18 / 18)$. Tying the stay sutures was not needed to overcome any leakage from the center of the purse string suture.

Overall, the purse-string technique closed the corporotomies successfully in $18 / 18$ (100\%) cases, exclusively without tying the stay sutures.

\section{DISCUSSION}

In penile prosthesis implantation surgery, suturing the corporotomies by running sutures is more capable of achieving watertight sealing, decreasing the probability of hematoma formation. However, puncturing the IPP cylinders is a possible risk, particularly with occasional implanters. Meticulous suturing is necessary, at the cost of longer operative time. In 1993, Montague ${ }^{[13]}$ proposed sutureless closure of corporotomies, where the horizontal mattress stay sutures that hold the corporotomies open are used to close the corporotomy after device implantation. The 'Current Recommendations From the International Consultation on Sexual Medicine for Penile Prosthesis Surgery,'2016, state that iatrogenic injury, most commonly by a suture, has motivated many surgeons to use the corporotomy stay sutures for closure in a mattressstitch manner, instead of running a watertight stitch, to decrease the risk of inadvertent cylinder puncture ${ }^{[9]}$. A further refinement of corporotomy closure includes the use of oxidized regenerated cellulose (Surgicel Fibrillar) as a hemostatic adjunct that reduced postoperative drain output. They applied oxidized regenerated cellulose to 32 patients underwent IPP implantation. They noted that it was associated with a decrease in the drain output postoperatively. However, they did not propose that if it was a substitute to drain placement or they did not comment on the time of the operation ${ }^{[14]}$. In comparison to the present study, no drain was inserted in the wound and no postoperative hematoma was reported.

Shaeer's purse-string corporotomy closure described herein demonstrates that the technique is relatively watertight, obviating the need to drain, and eliminates the risk of puncturing the cylinders, while retaining the virtue of tying the stay sutures in regard to a shorter operative time. Shortening of the penis or protruding implant tips were not noted in all cases where three-piece implants were inserted.

\section{CONCLUSION}

Shaeer's Purse-String Closure of Inflatable Penile Implant Corporotomies provides watertight closure with short operative time, as an alternative to oversewing and tying the stay sutures. 


\section{CONFLICT OF INTEREST}

There are no conflicts of interest.

\section{REFERENCES}

1. Mulhall JP, Bella AJ, Briganti A, McCullough A, Brock G. Erectile function rehabilitation in the radical prostatectomy patient. J Sex Med. 2010;7: 1687-98.

2. Gontero P, Fontana F, Zitella A, Montorsi F, Frea B. A prospective evaluation of efficacy and compliance with a multistep treatment approach for erectile dysfunction in patients after non-nerve sparing radical prostatectomy. BJU Int. 2005;95: 359-65.

3. Deveci S, Martin D, Parker M, Mulhall JP. Penile length alterations following penile prosthesis surgery. Eur Urol. 2007;51: 1128-31.

4. Wang R, Howard GE, Hoang A, Yuan JH, Lin HC, Dai YT. Prospective and long-term evaluation of erect penile length obtained with inflatable penile prosthesis to that induced by intracavernosal injection. Asian $\mathrm{J}$ Androl. 2009;11: 411-5.

5. Bettocchi C, Palumbo F, Spilotros M, et al. Patient and partner satisfaction after AMS inflatable penile prosthesis implant. J Sex Med. 2010;7: 304-9.

6. Minervini A, Ralph DJ, Pryor JP. Outcome of penile prosthesis implantation for treating erectile dysfunction: experience with 504 procedures. BJU Int. 2006;97: 129-33.
7. Bettocchi C, Palumbo F, Spilotros M, et al. Penile prostheses. Ther Adv Urol. 2010;2: 35-40.

8. Henry GD, Wilson SK, Delk JR, 2nd, et al. Revision washout decreases penile prosthesis infection in revision surgery: a multicenter study. J Urol. 2005;173: 89-92.

9. Levine LA, Becher E, Bella A, et al. Penile Prosthesis Surgery: Current Recommendations From the International Consultation on Sexual Medicine. J Sex Med. 2016;13: 489-518.

10. Anderson PC, Jain S, Summerton DJ, Terry TR. Surgical atlas. Insertion of an inflatable penile prosthesis. BJU Int. 2007;99: 467-82.

11. Bourne RB, Bitar H, Andreae PR, Martin LM, Finlay $\mathrm{JB}$, Marquis F. In-vivo comparison of four absorbable sutures: Vicryl, Dexon Plus, Maxon and PDS. Can J Surg. 1988;31: 43-5.

12. Tajirian AL, Goldberg DJ. A review of sutures and other skin closure materials. J Cosmet Laser Ther. 2010;12: 296-302.

13. Montague DK. Penile prosthesis corporotomy closure: a new technique. J Urol. 1993;150: 924-5.

14. Rozanski AT, Viers BR, Liu AG, et al. Oxidized Regenerated Cellulose (Fibrillar) Reduces Risk of Postoperative Corporal Bleeding Following Inflatable Penile Prosthesis Surgery. Urology. 2017. 